\title{
PROJEÇÕES INTERIORES E REPRESENTAÇÃO DO FEMININO EM SHAKESPEARE: GÊNERO, VIOLÊNCIA E FANTASIAS MATERNAS
}

\author{
Carlos Roberto Ludwig ${ }^{1}$
}

Resumo: Este ensaio discute as projeções do masculino sobre o feminino que provoca uma representação ambivalente e distorcida das personagens femininas em Shakespeare. Esta ambivalência masculina particular cria visões negativas sobre as personagens femininas e desencadeiam visões ludibriosas sobre o feminino, que parecem ser, em geral, figuras opacas nas peças de Shakespeare. Consequentemente, as figuras femininas são segregadas e são alvo de violência e negação nas peças. No caso de Macbeth, sua esposa inicia a peça como uma figura cuja força ajuda Macbeth a conquistar o trono. Contudo, no decorrer da peça há um afastamento progressivo que leva a negação e violência contra as personagens femininas. Essa discussão está fundamentada nos estudos sobre fantasias maternas de Adelman (1992) e a noção e interioridade de Maus (1995). A partir destas duas discussões, crio o conceito de projeções interiores para discutir a distorção criada pelas personagens masculinas sobre as femininas.

Palavras-chave: Projeções interiores; fantasias maternas; gênero; violência.

Abstract: This essay discusses the male projections on the feminine which provokes an ambivalent and distorted representation of the female characters in Shakespeare. This particular male ambivalence creates negative views on the female characters and unleashes deceitful views on the feminine that seems to be generally obfuscated figures in Shakespeare's plays. Consequently, the female figures are abrogated and turn out to be targets of violence and negation in the plays. For example, in Macbeth, his wife begins the play as a figure whose strength helps Macbeth to conquer the throne. However, during the play there is a progressive separation that leads to negation and violence against the female characters. This discussion is based on the studies about maternal fantasies by Adelman (1992) and the notion of inwardness discusses by Maus (1995). Parting from these discussions, I build up the concept of inward projections in order to discuss the distortion created by the male characters about the feminine.

Keywords: Inward projections; maternal fantasies; gender; violence.

1 Docente do Curso de Letras e do Programa de Pós-Graduação em Letras da Universidade Federal do Tocantins, Campus de Porto Nacional. 
É possível perceber uma forte oposição entre o indivíduo e o estado na obra de Shakespeare. De um lado, o desejo individual masculino entra em conflito com o Estado e sua necessidade de ordem, como acontece em Macbeth e Hamlet, por exemplo. Nesse conflito, as personagens femininas são representadas como figuras que passam ao largo dessas relações e conflitos, como personagens maléficas. Isso acontece em Coriolanus e Macbeth, por exemplo, em que são representadas como manipuladores e determinadores das decisões masculinas. Ou então, tornam-se alvos fantasmáticos sobre os quais são projetadas as angústias e fantasias sexuais masculinas, como reações negativas da consciência das personagens masculinas, como acontece em Hamlet, Otelo e Rei Lear. Esta ambivalência masculina particular nas peças de Shakespeare cria não apenas visões negativas sobre as personagens femininas, mas também desencadeia projeções interiores enganosas sobre as personagens femininas, que parecem ser, em geral, figuras apagadas e opacas nas peças. Essas visões e projeções são o resultado da percepção do olhar masculino que distorce a imagem sobre elas.

Assim, é possível perceber uma relação intrínseca entre os dispositivos miméticos e projeções interiores do masculino na obra de Shakespeare, porque as mulheres são vistas através da visão do masculino. A percepção sobre as mulheres é estritamente condicionada à imaginação e representação do masculino, o que cria imagens desfiguradas sobre as mulheres. Devemos perguntar se personagens femininas em Shakespeare são personagens muito mais independentes ou estão muito mais ligadas às fantasias e projeções fantasmagóricas da reação interior negativa dos protagonistas masculinos. Nesse sentido, segundo Adelman (1992), as mulheres em Shakespeare são construídas como fantasias maternas masculinas, que aparecem como reações perturbadoras e angustiantes para com as atitudes femininas. As personagens masculinas pensam que as mulheres são naturalmente constituídas como eles as imaginam ser; mas, ao invés disso, é apenas sua visão que deforma as representações femininas de acordo com suas próprias projeções negativas. Muito do que conhecemos sobre as personagens femininas são fruto do que as personagens masculinas dizem sobre elas. Por exemplo, em Hamlet, vemos Gertrudes principalmente através da fala e da visão de Hamlet, e raramente através de sua própria voz. Gertrudes tem poucas falas na peça, o que não nos permite descobrir sua subjetividade. Ela não tem desejos; ninguém pode saber se ela se casou com Claudius por necessidade, conveniência ou amor sincero. Nada nos é dito na peça, a não ser o que Hamlet fala sobre ela. A única coisa percebida é que ela quer a felicidade de seu filho. Da mesma forma, Lady Macbeth é apresentada como um espelho das dimensões negativas de Macbeth. Sua coragem e força refletem a ambição e desejo de Macbeth, em vez de seu próprio desejo.

As figuras femininas são, de fato, projetadas no texto como as dimensões mais negativas do masculino como resultado de um construto social e simbólico da época. No entanto, além de questionar o que são as projeções interiores, é importante perguntar "quem é o outro por trás da personagem masculina": com efeito, essa projeção interior é um conjunto de fenômenos relacionados à percepção do outro, como algo imaginário, criado pela visão do masculino como imagens distorcidas e negativas, que refletem as próprias dimensões 
interiores do masculino sobre o feminino. As mulheres não são o que eles realmente parecem, mas o que as personagens masculinas querem que elas sejam.

A representação negativa das personagens femininas é tão intensa que até alguns críticos de Shakespeare chegam a considerá-las personagens femininas maléficas. Em geral, muitos críticos do sexo masculino tendem a criar lacunas e omissões no tocante à representação do feminino em Shakespeare, como se não percebessem os artifícios miméticos reais que Shakespeare e seus mecanismos para representar as figuras femininas. Mas, na verdade, existe uma lacuna entre as falas e a visão masculinas e a representação de personagens femininas, que vela a caracterização das mulheres nas peças, como resultado da linguagem e construção dramática de Shakespeare, como também de construtos sociais e simbólicas herdados da tradição ocidental. Assim, alguns críticos chegam a cooperar, corroboram e confirmar pontos de vista das personagens masculinas de Shakespeare. Um exemplo muito intrigante é de Auden (2002) que afirma que Desdemona, em Othello, "dados alguns anos a mais da influência de Otelo e Emilia ela [Desdêmona] poderia muito bem, sente-se, ter tido um amante" (1948, p. 105). Aqui, podemos ver que Auden contribui e confirma a visão negativa de Otelo sobre Desdêmona na peça de Shakespeare. O autor analisa-a em termos de ponto de vista da personagem masculina. Ele afirma que Desdêmona é culpada por seu ciúme de seu marido e de sua própria morte. O crítico não é tão crítico como ele deveria ser. Ele lê a peça como um leigo leria. Mas o que acontece, na verdade, é que os mecanismos miméticos criados por Shakespeare são tão convincentes que o público e os críticos chegam a pensar que ela de fato é culpada.

\section{Projeções Interiores e a Oposição entre Interioridade e Aparências}

Começo essa discussão abordando um problema recentemente retomado nos Estudos da Renascença: as diferenças entre interioridade e exterioridade, que não são facilmente percebidas pelo espectador. A noção de aparências enganosas é amplamente representada no drama shakespeariano. O paradoxo entre a aparência exterior ostensiva, que era supostamente falsa, enganosa e perigosa, e a interioridade verdadeira, ainda que imperceptível aos sentidos, não é um problema desconhecido para contemporâneos de Shakespeare. Essa dicotomia foi um traço perceptível no Renascimento, especialmente na era de Shakespeare. Os autores da época estavam muito conscientes e preocupados com as relações entre o exterior e interior nos discursos políticos, teológicos e literários dos séculos XVI e XVII. Kathrine Eisaman Maus, em sua obra Inwardness and Theater in the English Renaissance (1995), analisa interioridade em oposição à exterioridade em termos da diferença entre um eu interior indizível e um exterior teatral e intencionalmente modulados. Ela estuda as angústias epistemológicas causadas por esta lacuna, as práticas sociais inventados para mantê-las e os propósitos políticos e sociais para os quais eles servem. Apesar das controvérsias sobre a consciência de uma interioridade no período, Kathrine Maus observa que inúmeros discursos da época eram usados para apresentar distinções entre interior e exterior como um lugar comum na Renascença. Portanto, essas angústias, exaustivamente apresentados em Shakespeare, não são obra de um visionário. Era um recurso retórico muito familiar nos séculos XVI e XVII. Por exemplo, Edward Jorden em A Brief Discourse of a Diseased Called 
the Suffocation of the Mother observa as diferenças entre as causas internas e externas da doença; John Dod e Robert Cleaver distinguem duas principais formas de violação dos Dez Mandamentos: transgressões interiores e exteriores; William Perkins distingue, em The whole treatise of the cases of the conscience (1606), entre a tristeza interior e exterior, limpeza interior e exterior, arrependimento interior e exterior, veneração interior e exterior, e assim por diante.

Neste mesmo sentido, Hamlet percebe que o mundo é moldado pelas aparências apagadas e traiçoeiras e, por isso, sente angústia, pois ele quer que seus trajes expressem seu lamento (interior) pela morte de seu pai:

Seems, madam! nay it is; I know not 'seems.'

'Tis not alone my inky cloak, good mother,

Nor customary suits of solemn black,

Nor windy suspiration of forced breath,

No, nor the fruitful river in the eye,

Nor the dejected 'havior of the visage,

Together with all forms, moods, shapes of grief,

That can denote me truly: these indeed seem,

For they are actions that a man might play:

But I have that within which passeth show;

These but the trappings and the suits of woe. (SHAKESPEARE, 2000, p. 697)

De acordo com Maus, é difícil definir o que é real para Hamlet. A simples existência de um hiato entre os sinais e o que eles significam parecem marcas insuficientes de sua consequência. Kathrine Maus argumenta que

Hamlet distingue entre os rituais teatrais externos de luto e uma ansiedade invisível interior. Suas roupas, seus suspiros, suas lágrimas não são suficientes para transmitir a sinceridade de Hamlet, não porque eles são falsos, mas porque podem ser falso, porque alguém pode usá-los falsamente. (1995, p. 01)

A convicção de Hamlet de que a verdade é indizível, deprecia qualquer tentativa de expressá-la. De acordo com Maus, as distinções entre o interior e o exterior superam essa visibilidade - e, portanto, a validade da existência de um interior altamente valorizado é intocável. O exterior, pelo contrário, era considerado falso, parcial, enganador e insubstancial (MAUS, 1995, p. 04-05). Os polemistas da era Tudor e Stuart como Stubbes, Northbrooke, Rankin, Gosson e Prynne reconheciam a separabilidade de um interior favorecido e "verdadeira", em oposição a um exterior socialmente visível, ainda que falsificável e teatralizado. Eles depreciam tal separação, ao afirmar que os homens deviam parecer exteriormente o que são e sentem interiormente: "As pessoas e as coisas são interiormente"; "As pessoas e as coisas parecem exteriormente". (MAUS, 1995, p. 4-5).

Portanto, o sentimento de que era necessário mostrar a interioridade exteriormente tinha criado a possibilidade de construir um sentido de que o que as personagens femininas devia ser era 
algo real e verdadeiro. Assim, é possível que as projeções interiores do masculino sobre as figuras femininas fossem reações negativas ao feminino em geral, que reproduziam simbolicamente os construtos sociais e culturais da Renascença, originalmente como resultado de discursos médicos, morais e teológicos dos séculos XVI e XVI. Estas projeções interiores criaram imagens e conceitos falsos e enganosos para o Outro, o que distorceu e manipulou a posição social e papéis em termos de sexo, geralmente apresentado como construções sociais e culturais tomadas como legítimas. Se se considerar que as aparências (exterioridade) e os discursos deviam apresentar os sentimentos interiores e pensamentos, assim, as personagens masculinas de Shakespeare podiam conceber que a aparência de uma mulher, como Hamlet afirma, o seu exterior, gestos, atitudes e comportamentos deviam mostrar seu interior. Além disso, o público imediatamente aceitaria que a aparência externa e os discursos eram algo natural e verdadeiro. Como consequência, dificilmente questionariam a possibilidade das concepções do sexo masculino sobre as mulheres como projeções masculinas de suas angústias, ansiedades e negação do feminino.

Neste sentido, de acordo com o conceito psicanalítico de projeção, a imagem especular é o reflexo do próprio corpo na imagem do Outro, que constitui, em seguida, a identificação de uma totalidade na imagem deste Outro. Contudo, é apenas uma identificação falsa criada por uma imagem, tendo a sensação de que ele é, na verdade, sua própria psique na totalidade. Embora Lacan (2003) identifique este problema no desenvolvimento, na identificação das crianças e constituição do eu, em alguns casos, é possível ver um continuum entre as ilusões da infância e da constituição da própria identidade na fase adulta. Neste caso, a imagem especular continua a ter os seus efeitos sobre o sujeito, como uma reação retroativa do sujeito mal formado, que imagina a construção de sua própria identidade somente na presença da imagem projetada no corpo do Outro, ou mais especificamente, no corpo materno. Isso é algo pertinente nas personagens masculinas de Shakespeare. Como afirma Adelman (1992), as personagens masculinas de Shakespeare constituem suas identidades mostrando tanto repulsa ao corpo materno. Neste sentido, o continuum de imagens da infância que iludem o sujeito no desenvolvimento psíquico tem reações negativas, que são mostrados pela agressão contra as figuras maternas e femininas. Neste ponto, as projeções do sexo masculino tornam-se imagens distorcidas que iludem as próprias personagens masculinas, o que eu defino como projeções interiores: as projeções interiores são uma constelação de sentimentos reativos e projetivos do sexo masculino que surgem nos instantes de crise, desencadeando zonas confusas, obscuras e ambíguas sobre a figura do Outro, seja ele o feminino, a bruxa ou a adúltera. São construídos de acordo com projeções sintomáticas do sexo masculino como uma tentativa de retornar a um estágio de origem para fugir desses momentos de crise. As projeções interiores em Shakespeare são constituídas principalmente pela angústia masculina que surgem como fantasias maternas e deformação da representação feminina.

\section{Fantasias Maternas e Projeções Interiores em Shakespeare}

Janet Adelman (1992), em seu estudo Suffocating Mothers: Fantasies of maternal origin in Shakespeare's plays, Hamlet to Tempest, analisa as fantasias maternas das personagens masculinas re-imaginadas como um retorno ao corpo materno. Mas esse retorno 
re-imaginado é revelado em termos de agressão e confronto com o corpo materno. O corpo feminino era, em geral, visto como um lócus do mal, perigo e morte para a criança do sexo masculino. Segundo ela, "as condições reais da infância teriam se integrado às representações culturais do corpo feminino para marcar esse corpo como o local da deformação e vulnerabilidade" (1992, p. 05). Esta visão negativa não só era projetada em termos de dispositivos dramáticos nas peças de Shakespeare, mas também como um constructo social reconstruído em suas peças, com base nos discursos médicos, morais e teológicos dos séculos XVI e XVII.

Em um período de fome, quando as crianças rotineiramente morriam, as mães eram consideradas responsáveis por essas mortes (ADELMAN, 1992, p. 04). Uma vez que o leite materno era considerado perigoso, até mesmo nocivo para a criança, a amamentação foi por vezes considerada a causa de morte de muitas crianças (ADELMAN, 1992, p. 06). Esse longo período de fome havia criado uma longa dependência do corpo materno, durante o qual as crianças foram supostamente submetidas, não só aos perigos, mas, principalmente, a uma dependência psicológica para com a mãe. A autora afirma que "o ventre era tradicionalmente entendido como a entrada para a morte e o local da mortalidade" (1992, p. 06). Assim, visões negativas sobre as mulheres eram normalmente associada por muitas analogias, que costumavam representá-las de forma tendenciosa e negativa.

Além disso, a amamentação por amas de leite era re-imaginada por crianças do sexo masculino como abandono. Diários e cartas da época mostram que os meninos imaginavam que tinham sido abandonados duas vezes: primeiro pela mãe, que o entregou a uma ama de leite, e depois novamente pela ama de leite, que o devolveu a sua mãe. Adelman afirma que,

A amamentação simplesmente deu a criança dois locais psíquicos de privação materna intensa ao invés de um só: primeiro, a rejeição materna original sinalizada pela amamentação; e depois o desmame - rotineiramente pela aplicação de absinto ou outra substância de sabor amargo no mamilo - e a separação abrupta da ama de leite que ele ou ela podia ter conhecido há dois ou três anos. (ADELMAN, 1992, p. 05).

Estas condições sociais efetivamente criaram uma percepção negativa sobre a amamentação como algo nocivo e perigoso para as crianças. Mas isso não tinha sido a única causa principal: a teoria aristotélica em sua Gênese afirma a dualidade entre masculino e feminino como uma dualidade "entre o masculino com o espírito ou forma e o feminino com a matéria, como se a mortalidade em si eram o sinal de deformação herdada pelo homem" (ADELMAN, 1992, p. 06). Tanto as condições sociais como as diversas crenças da época levaram a projeções negativas da "vulnerabilidade da criança no corpo da mãe / ama de leite" (1992, p. 06). Como se pode ver, a nutrição social e problemas congênitos médicos criaram projeções depreciativas sobre as mulheres, como se esses fatos fossem algo natural.

Essas ideias distorcidas foram projetadas pelos dramaturgos renascentistas e poetas, como Sidney, Spencer e o próprio Shakespeare. Por exemplo, em Richard III de Shakespeare, a fantasia de Richard de que o ventre de sua mãe tinha deformado seu corpo reitera simbolicamente que a mãe 
podia literalmente deformar fetos através da imaginação excessiva, seus desejos não controlados, seus desejos não naturais. E sua fantasia de asfixia no útero não era mais do que fato científico: muitos entendiam que os nascimentos como a resposta do feto ao suprimento inadequado de ar ou alimentos no útero. (ADELMAN, 1992, p. 06).

Além disso, mesmo o aborto espontâneo ou natural era cientificamente considerado responsabilidade da mãe, por causa do excesso de sangue, alimentos, ou até mesmo asfixia e estrangulamento do feto na barriga da mãe (ADELMAN, 1992, p. 06). Neste ponto, podemos perceber, em Shakespeare e nos discursos sociais da época, as projeções interiores do sexo masculino em relação ao corpo feminino, devido não às condições biológicas e naturais das mulheres, mas às crenças, discursos médicos e morais que pregavam e avaliavam negativamente as condições maternas como algo natural e intencional das mulheres.

Além disso, as projeções interiores do sexo masculino para com o corpo materno em Shakespeare se deve à ideia falaciosa e à imagem provocadas pelos discursos nesse retorno re-imaginado para o corpo materno, como uma maneira de projetar e impor o poder masculino como centro em qualquer ordem social. As ansiedades masculinas são projetadas nas figuras femininas como um núcleo de descarga psicológica de suas tensões interiores, tais como os desejos por prestígio político e poder sentidos pelos homens em momentos de crises psicológicas. Por exemplo, em Hamlet, ele está muito preocupado com o casamento de sua mãe, de modo que ele se torna muito distante do seu objetivo de vingança. Consequentemente, o corpo materno torna-se um núcleo de retardo para a sua ação. Seus discursos criam uma falsa imagem e ideia de que o problema em jogo não seja o assassinato de seu pai, mas o casamento de sua mãe com Claudius. Ele constrói uma falsa imagem de sua mãe de modo que ela é considerada cúmplice do crime e até mesmo adúltera. No entanto, não sabemos nada sobre o envolvimento de Gertrudes no crime ou se ele tenha sido adúltera de fato. A angústia interior de Hamlet em relação à morte de seu pai é projetada (redirecionada) à figura materna, o que o ilude o tempo todo e desvia-o do seu propósito: para vingar seu pai.

Assim, pode-se perguntar, “quem é Gertrudes exatamente?" Na verdade, ela nos é apresentada em geral pelas falsas projeções interiores de Hamlet, que vêm à tona em seus discursos. Ninguém conhece exatamente suas dimensões psicológicas, apenas o que Hamlet diz sobre ela. Esse é um artifício mimético criado por Shakespeare a fim de chamar a atenção do público não para o principal problema da peça, mas para as descrições distorcidas sobre a mãe de Hamlet. Portanto, entre o público e Gertrudes, Shakespeare interpõe a figuH ra de Hamlet, que realmente define a empatia do público para com seus sofrimentos e sua imagem ilusória de sua própria mãe. Sua reação é muito incisiva e o fato de ser uma mulher era a condição natural para que fosse considerada maligna e enganosa. Tal concepção era resultante de um constructo simbólico-cultural que refletia discursos morais e médicos daquele período. Embora fosse impossível perceber a subjetividade como algo verdadeiro na Renascença, as imagens negativas de Hamlet projetadas em sua mãe eram, no entanto, aceitas sem questionamento, porque se imaginava o exterior devia supostamente expressar o interior. Do contrário, uma pessoa seria considerada falsa e traiçoeira se ela/ele não manifestasse seu eu interior verdadeiramente através das aparências. Mas o ponto é que ninguém 
pode descobrir o eu interior de Gertrudes, mas apenas as projeções interiores de Hamlet sobre sua mãe, as quais surgem em seus solilóquios. Ele é insistentemente persuasivo em relação a isso, de modo que suas imaginações desviam a atenção do púbico para a figura da mãe com maléfica e enganosa. Além disso, suas reações são apresentadas através da violência e agressão contra sua mãe, principalmente na cena de seu quarto, no ato III, cena iv.3.

\section{Projeções interiores e Fantasias Maternas em Macbeth}

Em Macbeth, Adelman (1992) afirma que a figura materna não é "encarnada na figura de uma mãe em particular", mas é estendida em muitas personagens difusas, tais como as bruxas, Lady Macbeth, e até mesmo Duncan e Macdownwald (1992, p. 131). Adelman argumenta que as personagens masculinas supostamente constroem sua masculinidade na presença da mãe e na ausência do pai. Isto é particularmente válido para Hamlet, Otelo, Coriolano e Macbeth. Otelo e Macbeth criam a sua força e masculinidade na mãe re-imaginado em suas esposas. Macbeth só pode construir a sua masculinidade através da ausência, separação e segregação para a figura materna. Na verdade, como Hamlet, Macbeth é órfão e tem apenas figuras maternas para reforçar a sua masculinidade. Lady Macbeth tem a coragem de construir a sua virilidade, enquanto ele tem a força física para conquistar a coroa.

Adelman (1992) defende que as personagens masculinas constroem a sua masculinidade ao voltar imaginariamente ao corpo e útero maternos. Nos casos de Macbeth e Coriolano, eles são personagens que compõem a sua masculinidade fugindo da presença materna. Eles agem de forma progressiva, afastando-se de Lady Macbeth e Volumnia, como uma reação negativa à presença materna e como uma projeção negativa à impossibilidade de suportar a presença maternal, sentida por eles como algo ameaçador, mal, e maligno. No entanto, não é a personagem feminina real que cria esses sentimentos, mas apenas suas projeções interiores é a verdadeira causa dessas reações negativas.

Nesse sentido, Lady Macbeth é vista em Macbeth como um corpo materno coberta com imagens militares, o que lhe dá força para construir sua masculinidade. A constituição da masculinidade em Macbeth ocorre de forma paradoxal: escapar do corpo materno, mas também através da força das imagens militares maternas, o que lhe dá vigor para agir e determinar sua ação. No entanto, há uma espécie de ruptura progressiva em Macbeth da relação para com Lady Macbeth. Ele parece não mais precisar de sua coragem e sua força depois do assassinato. Ela é simplesmente descartada por ele. Essa reação pode ser vista como projeções internas de Macbeth, que projetam uma imagem de um soldado masculino e militar sobre o corpo da esposa, cuja força é indispensável para a sua conquista da coroa. Por exemplo, Macbeth diz à esposa: "Bring forth men-children only; / For thy undaunted mettle should compose / Nothing but males. (SHAKESPEARE, 1997, p. 41). Neste discurso, a coragem significa não só a força, mas também metal, o que se configura como uma tentativa de investir o corpo feminino com uma armadura militar. Além disso, o desejo de ter apenas filhos do sexo masculino assinala projeções reativas sintomáticas das características masculinas no corpo feminino. Assim, a única coisa que ele espera dela é ter filhos, a fim de evitar a presença da "fragilidade" do sexo feminino. Por meio da metáfora do imaginário de metais, Lady Macbeth "torna-se praticamente um ser do sexo masculino, composto de 
metal duro do qual o homem é feito" (ADELMAN, 1992, p. 139). Seus filhos devem ser como soldados armados, que não possuem o interior feminino. De modo similar, como um espelho de Macbeth, ela também quer que os agentes do mal a "dessexuem” (unsex me). Assim, ela tem um papel funcional que apenas revela as fantasias e projeções interiores do mal de Macbeth sobre ela. Adelman diz que "se masculinidade sanguinário de Macbeth é em parte uma resposta ao desejo de Lady Macbeth, de fato uma extensão da sua vontade, essa metáfora irá simultaneamente representar a maneira de escapar de seu poder." (1992, p. 138). Psicanaliticamente, ela é supostamente seu alter ego que transforma sua bondade em crueldade e agressão.

Além disso, em Macbeth outras representações femininas são investidas com imagens militares. Por exemplo, a justiça e a Fortuna: "No sooner justice had with valour arm'd" (SHAKESPEARE, 1997, p. 9). Nesta descrição, a Fortuna recebe características militares, que correspondem à própria imagem e aos propósitos guerreiros de Macbeth. Nesse mesmo sentido, Bellona é também descrito como: “Till that Bellona’s bridegroom, lapp'd in proof, / Confronted him with self-comparisons," (SHAKESPEARE, 1997, p. 9). Outras figuras femininas são construídas na peça de forma militarizada, a fim de ajudá-lo a cumprir e projetar seus propósitos e desejos malignos. É o que podemos ver na descrição abaixo que um soldado faz da batalha:

And fortune, on his damned quarrel smiling,

Show'd like a rebel's whore: but all's too weak:

For brave Macbeth - well he deserves that name -

Disdaining fortune, with his brandish'd steel,

Which smoked with bloody execution,

Like valour's minion carved out his passage

Till he faced the slave; (SHAKESPEARE, 1997, p. 7).

A identidade de Macbeth é construída com base na violência e agressão contra o corpo materno. Mais uma vez, as projeções interiores de Macbeth surgem como uma reação negativa ao corpo materno. A Fortuna aqui é vista como a prostituta de um rebelde, usada apenas como que um objeto para fornecer aos homens a força militar para continuar lutando. Neste sentido, Adelman (1992) argumenta que essa construção da identidade é imaginada como "um parto totalmente isentos de mulheres, imaginada, de fato, uma família só de homens, composta apenas por homens, em que o pai pode ser totalmente restaurado ao poder." (1992, p. 139). Esta descrição da batalha sugere o confronto entre os leais e os desleais, o masculino e o feminino. De acordo com Adelman,

A substituição metafórica da Fortuna para Macdonwald transforma a batalha em uma competição entre o masculino e o feminino; com efeito, ele faz a afirmação do nome Macbeth - "bravo Macbeth" - contingente de sua vitória sobre o feminino. [...] A identificação de Macbeth como servo do valor redefine a batalha como uma disputa entre o casal Fortuna / Macdonwald metade feminino e o casal Valor / Macbeth totalmente masculino. Metaforicamente, Macdonwald e Macbeth 
assumem as qualidades do sexo feminino não confiável e o macho heroico; a batalha de Macbeth contra a fortuna acaba por ser sua batalha contra Macdonwald, porque os dois são funcionalmente o mesmo. [...] Com efeito, então, a batalha que suporta o reino do pai desempenha o papel da criação de uma conquista erótica exclusivamente masculina que marca a sua conquista pelo seu triunfo sobre um corpo feminizado, ao mesmo tempo o da Fortuna e Macdonwald. (1992, p. 142).

A ausência e a negação materna é o meio de criar a identidade masculina. As figuras femininas, ou os valores investidos com características maternas, tornam-se os meios de constituição de identidade com violência masculina. As figuras femininas em Shakespeare não são de fato personagens reais, que poderiam ser tomadas a partir de qualquer imagem do período, mas eles são construções evasivas e opacas de projeções interiores do masculino, que definia e determinava os papéis sociais, as condutas e os comportamentos do feminino.

Assim, a fim de construir o poder paterno e masculino, é necessário negar presença feminina da mãe e constituir uma imagem bem sucedida e satisfatória de poder, vitória e domínio sobre ela. Neste sentido, Adelman (1992) afirma que o "ato de agressão contra o corpo feminino, com sua fantasia de auto-nascimento, marca a passagem de Macbeth para a contenda que vai definir sua masculinidade, em parte, mediante a atribuição da feminilidade contaminada para Macdonwald" (1992, p. 143). Além da transferência e feminilização do corpo de Macdonwal, Macduff é denominado na peça como "homem nascido de nenhuma mulher", ou seja, ele foi arrancado do ventre de sua mãe antes do tempo por meio de uma cesariana. Essa associação sugere que apenas um homem com pouca ou nenhuma influência materna pode restaurar a harmonia original na Escócia. De acordo com Adelman,

mas ao atribuir seu poder ao fato de ele ter sido prematuramente arrancado do ventre de sua mãe, isso causa a sensação de que a separação violenta da mãe é a marca do homem bem sucedido. [...]. Além disso, a ambivalência que molda a figura de Macduff forma semelhantemente a estrutura dramática da própria peça. Ostensivamente preocupado em restaurar a ordem natural no final, a peça tem como base esta ordem sobre a exclusão radical do feminino. (1992, p. 144).

Neste ponto, de acordo com os constructos da época, o público poderia reagir positivamente à afirmação da segregação das mulheres. Em termos de convenção dramática, o público aceitaria a possibilidade de os homens serem bem sucedidos somente se escapassem e negassem a presença feminina. A ausência, negação e agressividade para com as figuras femininas não só acontece com Macbeth, mas em outras partes da peça. Macduff abandona sua família. Tanto Lady Macduff como Malcolm questionam a necessidade de abandonar sua família. Adelman afirma que

Este abandono inexplicável qualifica severamente a força de Macduff como exemplo central de uma masculinidade saudável da peça, que pode incluir a possibilidade de relacionamento com as mulheres: a peça parece investir as relações familiares doentias em Macbeth e a possibilidade de relações saudáveis em Macduff; e ainda 
descobrimos dramaticamente que Macduff tem uma família só quando ouvimos que ele a abandonou. Dramática e psicologicamente, ele assume o poder masculino total somente quando ele perde sua família e torna-se energizado pela perda, convertendo seu pesar na tonalidade mais "viril" de vingança. (1992, p. 144).

Outro elemento importante na peça é que as figuras femininas desaparecem progressivamente na peça: se Lady Macbeth era a princípio a fonte de terror, ambição e coragem, posteriormente ela se torna cada vez mais uma "esposa meramente impotente", com medo e alienada dos alvos de seu marido, morrendo fora do palco, registrado apenas com um grito de uma mulher. Da mesma forma, as bruxas, que estavam muito presentes no início da peça, tornam-se progressivamente ausentes, ou ainda, são progressivamente extintas da peça. Esses dados sugerem que, em termos de construção mimética, figuras femininas são amplamente concebidas como um mecanismo para mostrar as projeções interiores do sexo masculino, que são apresentadas como uma espécie de espelho escuro de indivíduos masculinos, utilizadas apenas para construir a sua identidade e masculinidade. Assim, como resultado deste dispositivo mimético e agressão, essas representações das figuras femininas tornam-se um meio de auto-interação e relação ativa que mostram que as mulheres estão condenadas a serem responsabilizadas pelo fracasso e dependência masculinos. Portanto, as figuras femininas como as bruxas, Lady Macbeth e Lady Macduff tornam-se figuras alienadas na peça (cf. GREENBLATT, 1984). Consequentemente, tornam-se um núcleo fantasmático para projeções interiores negativas das personagens masculinas, sempre visível em termos de violência e agressão.

Conforme as figuras femininas desaparecem na peça, as projeções malignas do masculino são suprimidas e, em seguida, a ordem natural e a harmonia podem ser restabelecidas. Essa é a projeção do desejo masculino. Portanto, somente através da negação, o poder do pai retorna ao estado original para definir a ordem das coisas. O exemplo mais emblemático disso em Shakespeare é o movimento da floresta de Birnam em Macbeth. De acordo com Adelman, os galhos das árvores Birnam são o emblema de uma "árvore de família estritamente patriarcal" (1992, p. 145) da qual as mulheres foram segregadas. Mas essa árvore genealógica é totalmente masculina: os filhos de Duncan, filhos de Banquo, Siward e seus filhos. Não há filhas e não há qualquer menção às mães nessas árvores genealógicas. Adelman afirma que "somos levados tanto quanto possível aqui à fantasia da família sem mulheres. Nesse sentido, a floresta de Birnam é o emblema perfeito da natureza que triunfa no final da peça: Natureza sem possibilidade generativa, a natureza sem as mulheres" (1992, p. 145).

Portanto, a peça gira em torno da necessidade de restauração da ordem natural, num mundo construído sem mulheres. No final, "a peça cria as bases para esta ordem sobre a exclusão radical do sexo feminino” (ADEMAN, 1992, p. 144). Se as peças excluem amplamente a presença feminina, então podemos considerar que este fenômeno acontece porque são vistas como figuras obscuras e devido a dispositivos miméticas que desencadeiam e mostram projeções interiores do sexo masculino. Suas representações são vistos como constructos sociais e simbólicos que lhes dão uma condição determinada e negam-lhes voz social e cultural. As mulheres em Shakespeare são por sinal apenas projeções dos desejos masculinos e uma construção simbólica do que os homens querem que eles sejam. 
ADELMAN, Janet. Suffocating Mothers: fantasies of maternal origin in Shakespeare's plays, Hamlet to Tempest. New York: Routledge, 1992.

AUDEN, W. Othello: New critical essays. New York: Routledge, 2002.

GREENBLAT, Stephan. Renaissance Self-Fashioning: From More to Shakespeare. Chicago: The University of Chicago Press, 1984.

LACAN, J.. Escritos. Rio de Janeiro: Jorge Zahar, 1998.

MAUS, Katharine Eisaman. Inwardness and Theater in the English Renaissance. Chicago e London: University of Chicago Press, 1995.

SHAKESPEARE, William. Complete Works. Londres: Wordsworth, 2007.

SHAKESPEARE, William. Hamlet. Londres: Arden, 2000.

SHAKESPEARE. Macbeth. Londres: Arden, 1997. 